\title{
License Structure for Multi-Module Facilities
}

August 2010

The INL is a

U.S. Department of Energy National Laboratory operated by

Battelle Energy Alliance

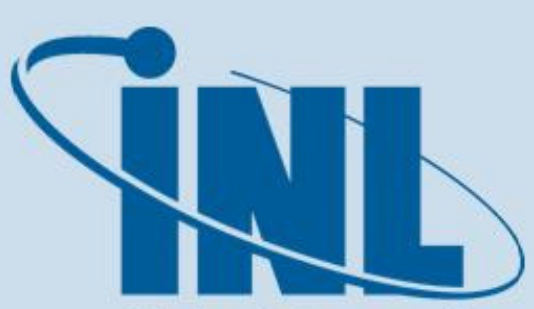

Idaho National Laboratory 


\section{DISCLAIMER}

This information was prepared as an account of work sponsored by an agency of the U.S. Government. Neither the U.S. Government nor any agency thereof, nor any of their employees, makes any warranty, expressed or implied, or assumes any legal liability or responsibility for the accuracy, completeness, or usefulness, of any information, apparatus, product, or process disclosed, or represents that its use would not infringe privately owned rights. References herein to any specific commercial product, process, or service by trade name, trade mark, manufacturer, or otherwise, does not necessarily constitute or imply its endorsement, recommendation, or favoring by the U.S. Government or any agency thereof. The views and opinions of authors expressed herein do not necessarily state or reflect those of the U.S. Government or any agency thereof. 


\section{License Structure for Multi-Module Facilities}

August 2010

Idaho National Laboratory

Next Generation Nuclear Plant Project

Idaho Falls, Idaho 83415

Prepared for the

U.S. Department of Energy

Office of Nuclear Energy

Under DOE Idaho Operations Office

Contract DE-AC07-05ID14517 
Next Generation Nuclear Plant Project

License Structure for Multi-Module Facilities

INL/EXT-10-18178

August 2010

Approved by:

Sim Kinsey for TKH
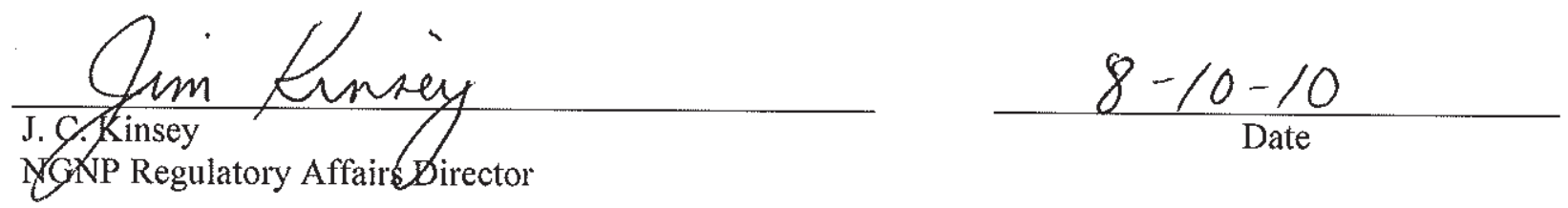

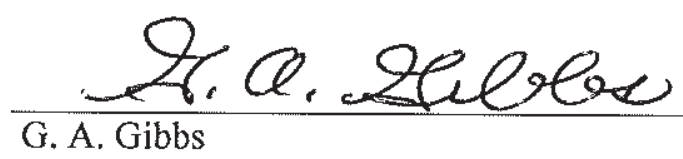

NGNP Project Director

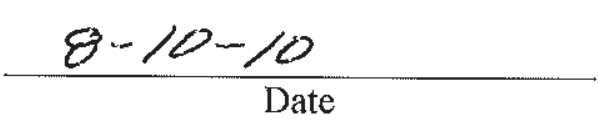




\begin{abstract}
The Next Generation Nuclear Plant (NGNP) Project is intended to be the prototype for multi-module commercial high temperature gas reactors (HTGRs) for process heat and/or electricity generation. Part of the objectives of the project are to establish the conditions that would govern or enhance the design, licensing, construction and operation of numerous, modular nuclear plants, particularly suited for industrial applications or that could reduce the risk of such projects.

A determination is desired regarding whether a multi-module reactor plant can be licensed with a single Nuclear Regulatory Commission (NRC) review, hearing, and safety evaluation report. If it is determined that a multi-modular reactor plant can be licensed under a single review/hearing process, the structure and the duration of the license for each module will also need to be determined. The purpose of this paper is to describe for the NRC the NGNP position on these two issues and obtain either NRC general concurrence or comments on the approach to these issues. While the current NGNP planning provides for only a single reactor module, the project is intended to provide the basis and establish a licensing framework that can be used by future commercial HTGRs and other reactor designs, including a variety of small modular reactor technologies, with configurations reflecting design standardization of multi-module plants.

Therefore, it is important to identify a path for addressing these modular reactor plant issues so that the resolution can be factored into the NGNP Project planning. The NGNP position is that a single combined license (COL) application can be submitted for a multi-modular reactor facility, the COL application can undergo a single NRC review/hearing process, and each module should be issued a separate license.
\end{abstract}




\section{CONTENTS}

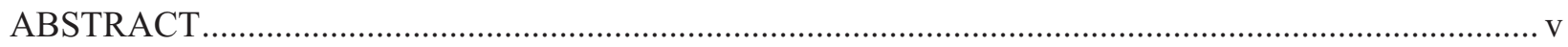

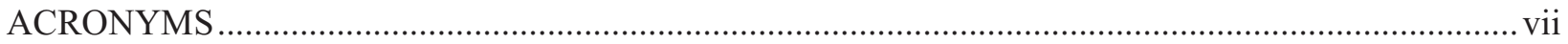

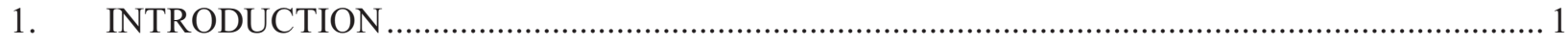

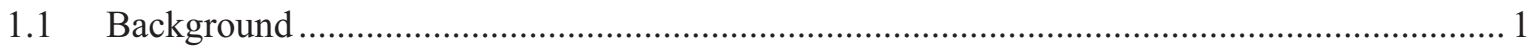

1.2 Purpose

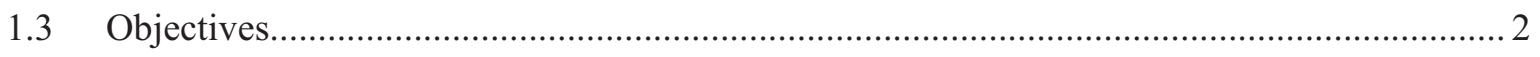

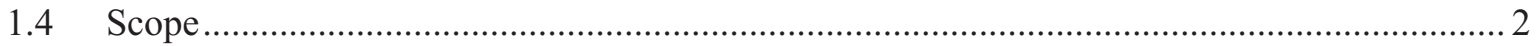

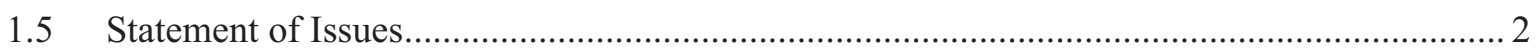

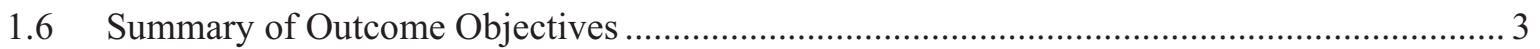

1.7 Relationship to Other NGNP Topics/Papers ................................................................. 3

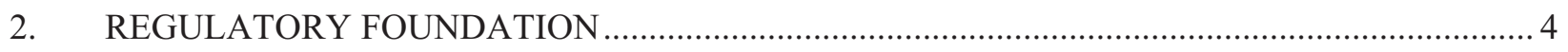

2.1 U.S. Regulatory Foundation for Multi-Module Reactor Plant Licensing .............................. 4

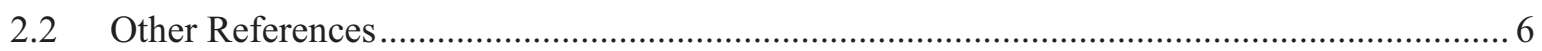

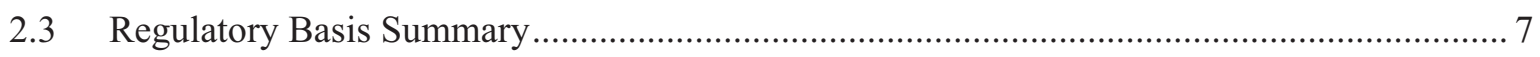

3. NGNP PROPOSED APPROACH FOR LICENSE STRUCTURE OF MULTI-MODULE

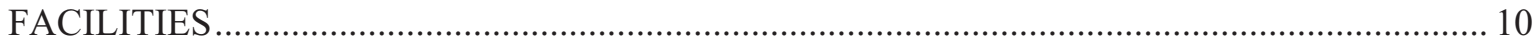

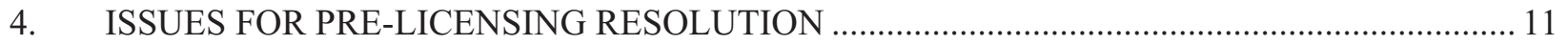

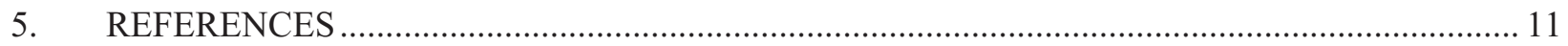




\section{ACRONYMS}

$\begin{array}{ll}\text { AEA } & \text { Atomic Energy Act } \\ \text { COL } & \text { combined license } \\ \text { DCD } & \text { design certification document } \\ \text { DOE } & \text { Department of Energy } \\ \text { ESP } & \text { early site permit } \\ \text { FSER } & \text { final safety evaluation report } \\ \text { GDC } & \text { general design criteria } \\ \text { HTGR } & \text { high-temperature gas reactor } \\ \text { MHTGR } & \text { modular high-temperature gas-cooled reactor } \\ \text { NEI } & \text { Nuclear Energy Institute } \\ \text { NGNP } & \text { Next Generation Nuclear Plant } \\ \text { NRC } & \text { Nuclear Regulatory Commission } \\ \text { PBMR } & \text { pebble bed modular reactor } \\ \text { PPE } & \text { plant parameter envelope } \\ \text { SER } & \text { safety evaluation report } \\ \text { SOC } & \text { statement of consideration } \\ \text { TVA } & \text { Tennessee Valley Authority }\end{array}$




\section{License Structure for Multi-Module Facilities \\ 1. INTRODUCTION}

\subsection{Background}

Existing regulations for licensing and oversight of nuclear power plants are predominantly directed at large, single unit stations. While some existing reactor plant operators have secured licenses for multiple units at a single site, these units were few (one to three) and large in power capacity. The existing regulatory framework does not consider the impact of placing many (e.g., upwards of ten), modular reactors having thermal power levels a fraction of large light water reactors (LWRs) on a single site.

The Next Generation Nuclear Plant (NGNP) Project is intended to be the prototype for multi-module commercial high temperature gas reactors (HTGRs) for process heat and/or electricity generation. Part of the objectives of the project are to establish the conditions that would govern or enhance the design, licensing, construction and operation of numerous, modular nuclear plants, particularly suited for industrial applications or that could reduce the risk of such projects.

Options for licensing the NGNP have been evaluated and a project licensing strategy has been formulated for proceeding with a Combined License (COL) application under 10 CFR Part 52, Subpart C. Additionally, as discussed in the NGNP Licensing Plan [Ref. 1], a licensing approach option for a future COL applicant is to proceed with one or more Early Site Permit (ESP) applications under 10 CFR Part 52, Subpart A. ${ }^{a}$

Current NGNP planning provides for licensing a single reactor module. However, the NGNP will be a demonstration project for follow-on commercial plants, some of which may include multiple reactor modules. This raises the need for the NGNP Project to investigate potential areas within Nuclear Regulatory Commission (NRC) requirements that may require clarification or revision in order to permit efficient licensing of these follow-on plants.

The NGNP Licensing Plan describes several topics where regulatory clarification for multiple-reactor modules may be needed. Several examples topics include:

- Number of reactors permissible within a single application/license

- Price-Anderson treatment ${ }^{\mathrm{b}}$

- Treatment of modules within an administrative (licensing) hearing

- Integrated risk

- Operator staffing

- License duration

- Annual fees assessed against each operating nuclear power plant

- Decommissioning plans

This paper addresses the topic of multi-module facility licensing structure (i.e., number of reactors addressed by a single application, license, and hearing; and multi-module license duration). Other topics

a. The project licensing strategy was documented in the Department of Energy (DOE) and NRC joint report to Congress: Next Generation Nuclear Plant Licensing Strategy - A Report to Congress, August 2008.

b. Section 170 of the Atomic Energy Act (known as the "Price-Anderson Act") establishes an indemnification and public liability scheme for damages resulting from nuclear power reactor accidents. In addressing Price-Anderson implications, the Energy Policy Act of 2005 (EPAct) included a section on the treatment of modular reactors but the language is directed at facilities with rated capacities described in terms of electrical kilowatts. 
above (i.e., Price-Anderson treatment, integrated risk, operator staffing, fees, and decommissioning plans) may be addressed in future papers, or through other industry initiatives. It should also be clearly noted that the licensing strategy being pursued for multiple HTGR units should lay the regulatory groundwork for the eventual licensing of other small modular reactor (SMR) types.

\subsection{Purpose}

The purpose of this paper is to describe the NGNP Project position on multi-module reactor plant licensing with respect to (a) combined license applications, NRC reviews, hearings, and safety evaluation documentation, and (b) the structure and duration of the license(s).

\subsection{Objectives}

The objectives of this paper are to:

- Determine whether a multi-module reactor plant can be licensed with a single NRC COLA review, safety evaluation report (SER), and hearing.

- If it is determined that a multi-module reactor plant can be licensed under a single application and review/hearing, then a second objective is to determine whether a single license should be issued for all modules or individual licenses issued for each module.

- Determine the starting date of the license(s) and duration of the license(s) for each module.

\subsection{Scope}

The scope of this paper can be applied to modular reactor designs that can have multiple, essentially identical reactor modules ${ }^{c}$. While the current NGNP planning provides for only a single reactor module in a single facility and/or at a single site, the project is intended to provide the basis and establish a licensing framework that can be used by future commercial HTGRs and other reactor designs with configuration reflecting design standardization of multi-module plants. Therefore, it is necessary to identify a path for resolving these modular reactor plant issues. This paper addresses the topic of multi-module facility licensing structure (i.e., number of reactors addressed by a single application, single hearing, and single/multiple license(s); and multi-module license duration). Other related topics (See Section 1.7) may be addressed in future papers.

\subsection{Statement of Issues}

The issues addressed in this paper are framed in the following questions regarding the NGNP licensing approach:

- Can a single application for a Part 52 Combined License (COL) include multiple (e.g., upwards of ten) essentially identical reactor modules?

- Can a single COL application for a multi-module reactor plant undergo a single NRC review with a single SER and NRC hearing?

- Would the size of the reactor make a difference in the ability to use a common licensing step for multiple, essentially identical reactors?

- Is the license duration for each module a period not to exceed 40 years from the date that the Commission finds the acceptance criteria in the license are met, in accordance with $\S 52.103(\mathrm{~g})$, for that module?

c. The term "essentially identical" here is in reference to the reactor plant and not necessarily to the secondary side end-use connections which may vary between modules at a given plant site. A facility COL application with multiple essentially identical reactor modules would describe the boundaries and secondary side end-use connections for the various modules. 
- In the case of issuing a separate license for each module at a site containing multiple modules, is a Commission policy issue decision necessary?

- In the case of issuing one license for a site of multiple modules, is Commission action necessary to approve unique staff recommendations regarding the framework of such a license?

- Does rulemaking or revision to law appear to be necessary in either case (single- or multiple-license issuance)?

\subsection{Summary of Outcome Objectives}

The objectives of this paper are to obtain NRC feedback and concurrence on an appropriate approach for multi-module reactor licensing to support reactor licensing objectives. Specifically, the NRC is requested to concur with the following statements or provide acceptable alternative statements:

- A single application for a Part 52 COL can include multiple, essentially identical reactor modules, regardless of the size of the reactors.

- The single application with multiple, essentially identical reactor modules (e.g., upwards of ten) can undergo a single NRC review, SER and NRC hearing.

- The license duration for each module within a single license authorization is a period not to exceed 40 years from the date the Commission finds that the acceptance criteria in the license are met, in accordance with $\S 52.103(\mathrm{~g})$, for that module.

- In the case of issuing a separate license for each module at a site containing multiple, essentially identical modules, no Commission policy issue decision is necessary.

- In the case of issuing one license for a site of multiple modules, legislative action will likely be necessary with respect to license durations and specific Commission action (i.e. regulatory changes) will likely be necessary to approve unique staff recommendations regarding the framework of such a license. [Since this is not the approach being pursued by the NGNP Project, it is not discussed in the Issues for Pre-Licensing Resolution (Section 4) portion of this white paper]

- No rulemaking or changes to law are necessary for multiple-license issuance within the structure described in this paper.

\subsection{Relationship to Other NGNP Topics/Papers}

The outcome of this paper may impact future papers involving related topics such as license application review fees, annual fees, Price-Anderson Act applicability, integrated risk, operator staffing, and nuclear-industrial island boundary, and decommissioning plans. 


\section{REGULATORY FOUNDATION \\ 2.1 U.S. Regulatory Foundation for Multi-Module Reactor Plant Licensing}

In the Atomic Energy Act (AEA), Congress did not specifically address the prospect of combining individual licenses for multiple reactor modules into a single combined license. Nevertheless, there is nothing in the legislative history of the AEA that explicitly precludes the possibility that the Commission may, under the authority of Section 161.h. of the AEA, combine into a single license the individual Part 52 combined licenses (COLs) for essentially identical reactor modules collocated at a single site. [Ref. 2] Relevant AEA references include the following:

Section 103, Commercial Licenses, states the following:

c. Each such license shall be issued for a specified period, as determined by the Commission, depending on the type of activity to be licensed, but not exceeding forty years, and may be renewed upon the expiration of such period.

Section 161, General Provisions, states the following:

In the performance of its functions the Commission is authorized to-

h. consider in a single application one or more of the activities for which a license is required by this Act, combine in a single license one or more of such activities, and permit the applicant or licensee to incorporate by reference pertinent information already filed with the Commission;

Historically, it has been NRC practice, under Part 50, to consider applications for multiple units at a single site in one review and one proceeding. Each reactor received its own docket number and separate operating license. This point is discussed further in SECY-02-0180, Legal and Financial Policy Issues Associated with Licensing New Nuclear Power Plants. [Ref. 3]

This section describes the relevant areas within NRC regulations that provide insight or direction regarding the concept of a single NRC review, SER, hearing, and COL for multi-module plants with essentially identical reactor modules. These relevant references from 10 CFR include the following:

Part 50, Domestic Licensing of Production and Utilization Facilities

\section{$\S 50.2$ Definitions}

Utilization facility means any nuclear reactor other than one designed or used primarily for the formation of plutonium or $U-233$.

\section{$\$ \mathbf{5 0 . 2 2}$ Class 103 licenses; for commercial and industrial facilities}

A class 103 license will be issued, to an applicant who qualifies, for any one or more of the following: To transfer or receive in interstate commerce, manufacture, produce, transfer, acquire, possess, or use a production or utilization facility for industrial or commercial purposes;

\section{Part 52, Licenses, Certifications, and Approvals for Nuclear Power Plants}

§52.1, Definitions, states the following:

Modular design means a nuclear power station that consists of two or more essentially identical nuclear reactors (modules) and each module is a separate nuclear reactor capable of being operated independent of the state of completion or operating condition of any other module co-located on the same site, even though the nuclear power station may have some shared or common systems. 
Early site permit means a Commission approval, issued under subpart A of this part, for a site or sites for one or more nuclear power facilities. An early site permit is a partial construction permit.

\section{$\$ 52.8$, Combining licenses; elimination of repetition}

$\S 52.8(c)$ The Commission may combine in a single license the activities of an applicant which would otherwise be licensed separately.

\section{Part 52, Subpart C-Combined Licenses}

\section{$\S 52.47$, Contents of applications; technical information}

(c)(3) An application for certification of a modular nuclear power reactor design must describe and analyze the possible operating configurations of the reactor modules with common systems, interface requirements, and system interactions. The final safety analysis must also account for differences among the configurations, including any restrictions that will be necessary during the construction and startup of a given module to ensure the safe operation of any module already operating.

\section{\$52.79, Contents of applications; technical information in final safety analysis report}

\section{$\$ 52.79(a)(1)($ ii) The proposed general location of each facility on the site}

\$52.103, Operation under a combined license, states the following:

$\$ 52.103(\mathrm{~g})$ The licensee shall not operate the facility until the Commission makes a finding that the acceptance criteria in the combined license are met, except for those acceptance criteria that the Commission found were met under $\$ 52.97(a)(2)$. If the combined license is for a modular design, each reactor module may require a separate finding as construction proceeds.

\section{Part 100, Reactor Site Criteria}

$\$ 100.11$, Determination of exclusion area, low population zone, and population center distance, states the following:

$\$ 100.11(b)$ For sites for multiple reactor facilities consideration should be given to the following:

(1) If the reactors are independent to the extent that an accident in one reactor would not initiate an accident in another, the size of the exclusion area, low population zone and population center distance shall be fulfilled with respect to each reactor individually. The envelopes of the plan overlay of the areas so calculated shall then be taken as their respective boundaries.

(2) If the reactors are interconnected to the extent that an accident in one reactor could affect the safety of operation of any other, the size of the exclusion area, low population zone and population center distance shall be based upon the assumption that all interconnected reactors emit their postulated fission product releases simultaneously. This requirement may be reduced in relation to the degree of coupling between reactors, the probability of concomitant accidents and the probability that an individual would not be exposed to the radiation effects from simultaneous releases. The applicant would be expected to justify to the satisfaction of the Commission the basis for such a reduction in the source term.

(3) The applicant is expected to show that the simultaneous operation of multiple reactors at a site will not result in total radioactive effluent releases beyond the allowable limits of applicable regulations. 


\subsection{Other References}

Other NRC guidance documents and position papers that address this topic include:

Regulatory Guide 1.206, [Ref. 4] Section C.I.13.1.1.2, Organizational Arrangement, states the following:

For new, multiunit plant sites, the COL applicant should describe the organizational arrangement and functions to meet the needs of the multiple units. The applicant should include in this discussion the extent to which the organizational arrangement and functions are shared between or among the units addressed in the application and describe the organizational arrangement and functional divisions or controls that have been established to preserve integrity between individual units and/or programs.

NUREG-0800, [Ref. 5] Chapter 1.0, Introduction and Interfaces, states the following:

I, Item 1: The principal aspects of the overall application are reviewed. These principal aspects include: the type of license requested, the number of plant units, [and] a brief description of the proposed plant location.

\section{SECY-02-0180, Legal and Financial Policy Issues Associated With Licensing New Nuclear Power Plants}

Discussion, page 4

Item 8. Licensing multiple modular reactors and the duration of a combined license (COL)

Can the NRC conduct a single set of licensing reviews and a single public hearing for multiple, nearly identical COL applications? What is the effective duration of a COL?

The Commission has the authority to conduct a single set of licensing reviews and a single public hearing for multiple COL applications for nuclear power plants of essentially the same design.

\section{SECY-01-0207, [Ref. 6] Legal and Financial Issues Related to Exelon's Pebble Bed Modular Reactor (PBMR)}

Discussion, page 4

Item 8. Number of licenses and license duration for one combined license (COL) for multiple reactors in 10 CFR Part 52

Congress did not specifically address the prospect of combining individual COLs for multiple reactor modules into a single combined COL. Nevertheless, there is nothing in the legislative history of the AEA that explicitly precludes the possibility that the Commission may, under the authority of Section 161.h. of the AEA, combine into a single license the individual Part 52 COLs for reactor modules of a substantially similar design collocated at a single site. If the Commission considers this course, it should also consider rulemaking to clarify: (i) the nature of "reactor modules" and modular designs whose licensing may be combined under the authority of Section 161.h. of the AEA and (ii) the process for making findings under 10 CFR 52.103(g) for reactor modules (and possibly the process for NRC staff inspection and publication of notices concerning completed inspections, tests, analyses and acceptance criteria (ITAAC) in 10 CFR 52.99.

The terms of operation for a single combined COL would be limited to 40 years from the date of issuance of the COL. Sequential 40-year terms for each reactor module are not possible in-as-much as a "single license" would be issued. Legislation recently submitted by the Commission addressing the matter of 40-year terms would, if enacted, permit the 40-year 
term of operation to begin when the Commission made the initial 10 CFR 52.103(g) finding, but would not permit sequential 40-year terms.

The staff has a concern with the effective duration of a design approval resulting from a multiple module license issued under 10 CFR Part 52. Therefore, if a single combined license is issued for multiple modules (nuclear reactors), then the license should be conditioned so that the design can be reviewed every 5 years without the constraints of the backfit requirement in 10 CFR 50.109 .

\subsection{Regulatory Basis Summary}

While recent NRC guidance and rulemakings under Part 52 clarify the topic of whether a multimodular plant can be licensed with a single review and set of hearings, it is appropriate to initiate a discussion on the topic to ensure consistency of interpretations between the NRC and the NGNP Project.

There are two possible paths regarding the concept of a single review and single hearing for multimodular reactor facilities ${ }^{\mathrm{d}}$ : (1) submitting a single combined license (COL) application but requesting a separate license for each module or (2) submitting a single COL application and requesting a single license for all modules.

NRC Regulation 10 CFR 52 governs the issuance of early site permits, standard design certifications, combined licenses, standard design approvals, and manufacturing licenses for nuclear power facilities. It clearly allows for multiple, essentially identical reactors to be included in a single COL application as discussed in the following references in Part 52 regarding COL applications for modular reactor designs:

- $\$ 52.8(\mathrm{c})$ states that "...the Commission may combine in a single license the activities of an applicant which would otherwise be licensed separately."

- $\$ 52.47(\mathrm{c})(3)$ specifies information to be included in a COL application such as the number of modules and other additional information needed for multi-module facilities.

- $\$ 52.103$, “Operation under a combined license," states that if the combined license is for a modular design, this section of the rule provides that each reactor module may require a separate finding as construction proceeds. In other words, the NRC may authorize fuel loading in one module while the other modules are under construction. Fuel load authorization for these additional modules would be granted when the specific module met the $\$ 52.103(\mathrm{~g})$ criteria.

There is precedence for providing a single review, a single SER, and a single hearing for a site with more than one similar reactor. For example, several COL applications have been filed under Part 52 by multiple utilities involving dual-unit AP1000 plants. While the design certification application for the AP1000 is for a single-unit facility, the AP1000 Final Safety Evaluation Report (FSER) [Ref. 7] does contain provisions for those instances where the COL applicant may seek to build more than one AP1000 at the same site. Specifically, the AP1000 FSER, Section 1.5, states the following:

...Because the AP1000 is designed as a single unit (i.e., no safety systems will be shared at a multiunit site), 10 CFR Part 50, Appendix A, General Design Criterion (GDC) 5, "Sharing of Structures, Systems, and Components," and 10 CFR 52.47(b)(3) do not apply to this design. Any applicant wishing to construct multiple units at a single site will be required to address these regulations in its application.

d. In the context of this discussion, it is assumed that the multi-module reactor application would be submitted under the 10 CFR Part 52 process. 
The Bellefonte COLA (an AP1000 design) [Ref. 8] provides descriptive information for the two-unit site, while referencing the AP1000 design certification document (DCD), which is a single-unit design certification. The TVA cover letter for the Bellefonte COL application states the following:

\section{The Tennessee Valley Authority (TVA) submits this application for a combined license for two AP 1000 advanced passive pressurized water reactors in accordance with the requirements contained in 10 CFR 52, "Licenses, Certifications and Approvals for Nuclear Power Plants," and the associated material licenses under 10 CFR 30, 40, and 70. These reactors will be identified as Bellefonte Units 3 and $4 \ldots$}

The Bellefonte COL application (FSAR Section 1.1) requested two Class 103 combined licenses to construct and operate two nuclear power plants under the provisions of 10 CFR Part 52 Subpart C. The NRC assigned two docket numbers for the two Bellefonte units, 52-014 and 52-015 (Units 3 and 4, respectively). It is expected that, based on prior practice, the NRC will issue two COLs, one for each unit (NPF-XX, NPF-XY). Furthermore, the NRC is conducting a single review for the Bellefonte Units 3 and $4 \mathrm{COL}$ application and has issued a single-draft SER and a single hearing notice that included both units.

The Nuclear Energy Institute (NEI) submitted a white paper on integrated modular plant licensing to the NRC in 2002. [Ref. 9] The white paper provided details of a proposed integrated approach to modular plant licensing, including a description of an approach to licensing that is based on issuance of a COL under 10 CFR Part 52 for each module of a modular facility. This approach is different from that proposed by Exelon in their May 10, 2001, PBMR submittal [Ref. 10], and assessed by the staff in SECY-01-0207. Exelon's position was that the Commission could, consistent with the language of Section 101 of the AEA and 10 CFR 50.10, issue a single license for multiple modules (reactors). NEI proposed that (1) the facility would be subject to a single set of licensing reviews and a single public hearing by the NRC, (2) each reactor module of a modular facility would be permitted to operate for the maximum period permitted by the AEA, and (3) a modular facility would be subject to a single NRC annual fee and be subject to a single Price-Anderson retrospective premium.

Under NEI's proposal, NRC would issue multiple COLs that would authorize construction of each module of the modular plant, and the COL application would identify the latest anticipated date that each reactor module will be completed based on the applicant's projections of the demand for electricity. If market conditions or other factors delay the planned construction of one or more modules, NEI proposed that a license amendment would be required to extend the "completion by" date(s) specified in the COL(s) and that the NRC decision to extend the "completion by" date(s) in the COL(s) would be focused on the safety impact of the delay and not involve reconsideration of the design and licensing bases of the reactor module(s). NEI further proposed that (1) the COL will embody NRC design approval for all modules proposed in the COL application, common systems, interfaces between the modules, interfaces with the site, etc.; (2) the duration of the NRC design approval is coincident with the term of the COL; and (3) the modular plant licensee may begin construction and deploy individual modules at any time during the license term, in accordance with the module completion dates specified in the COL.

License Duration - Assuming that a single license is issued for each module, the issue regarding license duration for each module has been already decided by NRC rulemaking. In the final Part 52 rule, Section 52.1 Definitions, a definition of modular design was added to explain the type of modular reactor design that the Commission intended to refer to in the second sentence of the existing $\$ 52.103(\mathrm{~g})$. As discussed in the Statement of Consideration (SOC) [Ref. 2], this special provision for modular designs was added to Part 52 to facilitate the licensing of nuclear plants, such as the modular high-temperature gas-cooled reactor (MHTGR) and Power Reactor Innovative Small Module (PRISM) designs, that consisted of three or four nuclear reactors in a single power block with a shared power conversion system. During the period that the power block is under construction, the Commission could separately authorize operation for each nuclear reactor when each reactor and all of its necessary support systems were 
completed. The Commission stated that the term "modular design" needed to be defined to aid future use of the current $\$ 52.103(\mathrm{~g})$ by distinguishing the intended definition from other currently used definitions for "modular design." Also, future combined license applicants for a multiunit site that would be similar to current multiunit sites (where each unit is similar in design but independent of all other units) could use this provision.

The license duration under Part 52 is defined under $\$ 52.104$, Duration of combined license, as a period not to exceed 40 years from the date that the Commission finds that the acceptance criteria in the license are met, in accordance with $\$ 52.103(\mathrm{~g})$. Since the $\$ 52.103(\mathrm{~g})$ finding is made for each module separately as it becomes ready to load fuel, there is no issue with maintaining the 40 -year duration for each module if separate licenses are granted for each module.

If a single license is granted for all modules, then the issue of license duration becomes more complicated. Since the AEA and NRC regulations state that a license duration cannot exceed 40 years (excluding renewal), then the single license start date would occur when the first module obtains its $\$ 52.103(\mathrm{~g})$ finding. In order for subsequent modules to achieve a 40 year license duration, changes to the AEA and NRC regulations appear to be required. Such changes would need to acknowledge the administrative option of issuing a single license for multiple utilization facilities (i.e., modules) at a single site and provide for the single license to have multiple beginning and end dates for each module. The single license would need to clearly differentiate the various modules and define the overall term of the license to encompass the $\$ 52.103(\mathrm{~g})$ finding dates for the various modules addressed by the license. This would appear to require that the law and the regulations allow for the overall duration of the license to exceed 40 years while limiting individual modules to operate for no more than 40 years (excluding renewal). Since this is not the approach being pursued by the NGNP Project, it is not discussed in the Issues for Pre-Licensing Resolution (Section 4) portion of this white paper. 


\section{NGNP PROPOSED APPROACH FOR LICENSE STRUCTURE OF MULTI-MODULE FACILITIES}

While the NGNP Project includes only a single reactor module, the demonstration project is expected to be followed by commercial plant deployments, most of which will likely include more than one reactor module. It is proposed that a single application for a Part $52 \mathrm{COL}$ can include multiple (e.g., upwards of ten) essentially identical reactor modules, regardless of size. Issues regarding integrated risk of multiple reactors would need to be addressed in accordance with any final NRC position or regulation on this topic at the time of COL application. The NGNP Project proposes that a single application would undergo a single NRC review and NRC hearing, and receive a single SER. Each module would preferably obtain its own unique docket number and its own unique license number. An application that includes a multimodule plant design would include the information requested in $\$ 52.157$ and HTGR information similar in scope and content to that specified in Regulatory Guide 1.206 for LWRs including analysis addressing the design and operation of all modules for the site and a description of the possible operating configurations of the reactor modules with common systems, interface requirements, and system interactions. The COL application for multiple reactor modules would also need to address the sequencing of module construction and the need for operating plant separation from construction activities (e.g., security, radiation protection) as modules are placed into service.

Absent the consideration of annual license fees (to be addressed in a separate white paper, or through other industry initiatives) and Price-Anderson, there appears to be little benefit of pursuing the option of multiple reactor modules authorized to operate under one license, since the benefits of a single review and single hearing can be achieved by submitting the multiple modules under one COL application requesting separate licenses for each module. The single license approach would likely require changes to the AEA and NRC regulations to allow full 40 year license duration for each module. Authorizing separate licenses for each module makes the start and end date of each module's license more straightforward.

The license duration under Part 52 is defined under $\$ 52.104$, Duration of combined license, as a period not to exceed 40 years from the date the Commission finds that the acceptance criteria in the license are met, in accordance with $\$ 52.103(\mathrm{~g})$. Since the $\$ 52.103(\mathrm{~g})$ finding is made for each module separately as it becomes ready to load fuel, there is no issue with maintaining the 40 -year duration for each module if a separate license is granted for each module.

Alternatively, if construction and operation of a multi-module reactor site were to be authorized under a single license, the NRC would need to establish a framework for such a license and determine how the license duration will be addressed given the sequential nature of each module's $\$ 52.103(\mathrm{~g})$ finding. While this alternate approach is not the NGNP preferred approach, resolution of the license duration issue and issuance of a single license for all essentially identical modules at a single site would not affect the underlying principle that there would be one review, one hearing, and one SER for all modules on the site. 


\section{ISSUES FOR PRE-LICENSING RESOLUTION}

In response to this paper and the proposed approach in Section 3, the NGNP Project requests NRC review and concurrence regarding the following regulatory positions:

- A single application for a Part $52 \mathrm{COL}$ can include multiple, essentially identical reactor modules (e.g., upwards of ten), regardless of reactor size.

- The single application with multiple reactor modules can undergo a single NRC review and NRC hearing, and receive a single SER.

- The license duration for each module within a single license authorization is a period not to exceed 40 years (without considering renewal) from the date the Commission finds that the acceptance criteria in the license are met, in accordance with $\$ 52.103(\mathrm{~g})$, for that module.

- Individual licenses can be issued for each module for a site containing multiple, essentially identical modules. No Commission policy issue decision is necessary to implement this approach.

- No rulemaking or legislative changes will be necessary for multiple-license issuance.

\section{REFERENCES}

1. PLN-3202, "NGNP Licensing Plan,” NGNP Project, Idaho National Laboratory, June 26, 2009.

2. 72 FR 49352. 10 CFR Part 52, Licenses, Certifications, and Approvals for Nuclear Power Plants; Final Rule, Statement of Consideration, August 28, 2007.

3. SECY-02-0180, "Legal and Financial Policy Issues Associated with Licensing New Nuclear Power Plants,: Item \#8, October 7, 2002.

4. Regulatory Guide 1.206, "Combined License Applications for Nuclear Power Plants (LWR Edition)," page C.I.13-3, June 2007.

5. NUREG-0800, "Standard Review Plan For The Review Of Safety Analysis Reports For Nuclear Power Plants," Chapter 1, pg 1.0-1, March 2007.

6. SECY-01-0207, "Legal and Financial Issues Related to Exelon's Pebble Bed Modular Reactor (PBMR)," Item \#8, November 20, 2001.

7. NUREG-1793, "Final Safety Evaluation Report Related to Certification of the AP1000 Standard Design," September 2004.

8. "Bellefonte Application for Combined License for Bellefonte Units 3 and 4," (Rev 0), October 30, 2007 [ADAMS Accession No. ML073110527].

9. NEI letter to NRC dated June 17, 2002, [ADAMS Accession No. ML021970596].

10. Exelon in their May 10, 2001, PBMR submittal [ADAMS Accession No. ML011420393]. 